\title{
Mouth Cancer Action Charter launched in Parliament
}

The Oral Health Foundation and Denplan launched their Mouth Cancer Action Charter at a face-to-face event in the Houses of Parliament.

The Charter proposes that GPs, pharmacists, care home and nursing staff should all be given enhanced training or further information about how to look out for signs and symptoms of mouth cancer to further improve early detection. Spotting signs early can increase someone's chances of survival from $50 \%$ to $90 \%$. The Mouth Cancer Action Charter highlights the following policy areas for change:

1. Conduct a government funded public health awareness campaign of the signs and symptoms of mouth cancer.

2. Improve access to routine dentistry to detect mouth cancers earlier and save lives.

3. Enable enhanced training of GPs to identify suspected mouth cancers and change the NICE guidelines so that more cases can be referred to secondary care.

4. Improve training programmes for healthcare staff to look for signs of mouth cancer.

5. Introduce free dental check-ups and treatment for mouth cancer patients to end the unfair financial burden placed on them.

6. Support the development of better technology to diagnose mouth cancers.

Members of Parliament, ministers and dental and health professionals were invited along to sign the Charter and demonstrate their support for its policy recommendations.

The Mouth Cancer Charter launch coincided with Mouth Cancer Action Month - the UK's biggest charity campaign for mouth cancer awareness. The campaign calls for more people to be 'mouthaware' by being able to recognise and act on any unusual changes to the mouth.

The Oral Health Foundation and

Denplan are concerned that mouth cancer referrals have significantly fallen over the pandemic period, while awareness of the major signs and symptoms of mouth cancer is very low. According to results from a recent MP survey, only $27 \%$ of MPs felt they were as well informed of the causes and symptoms of mouth cancer as they are of other leading cancers.

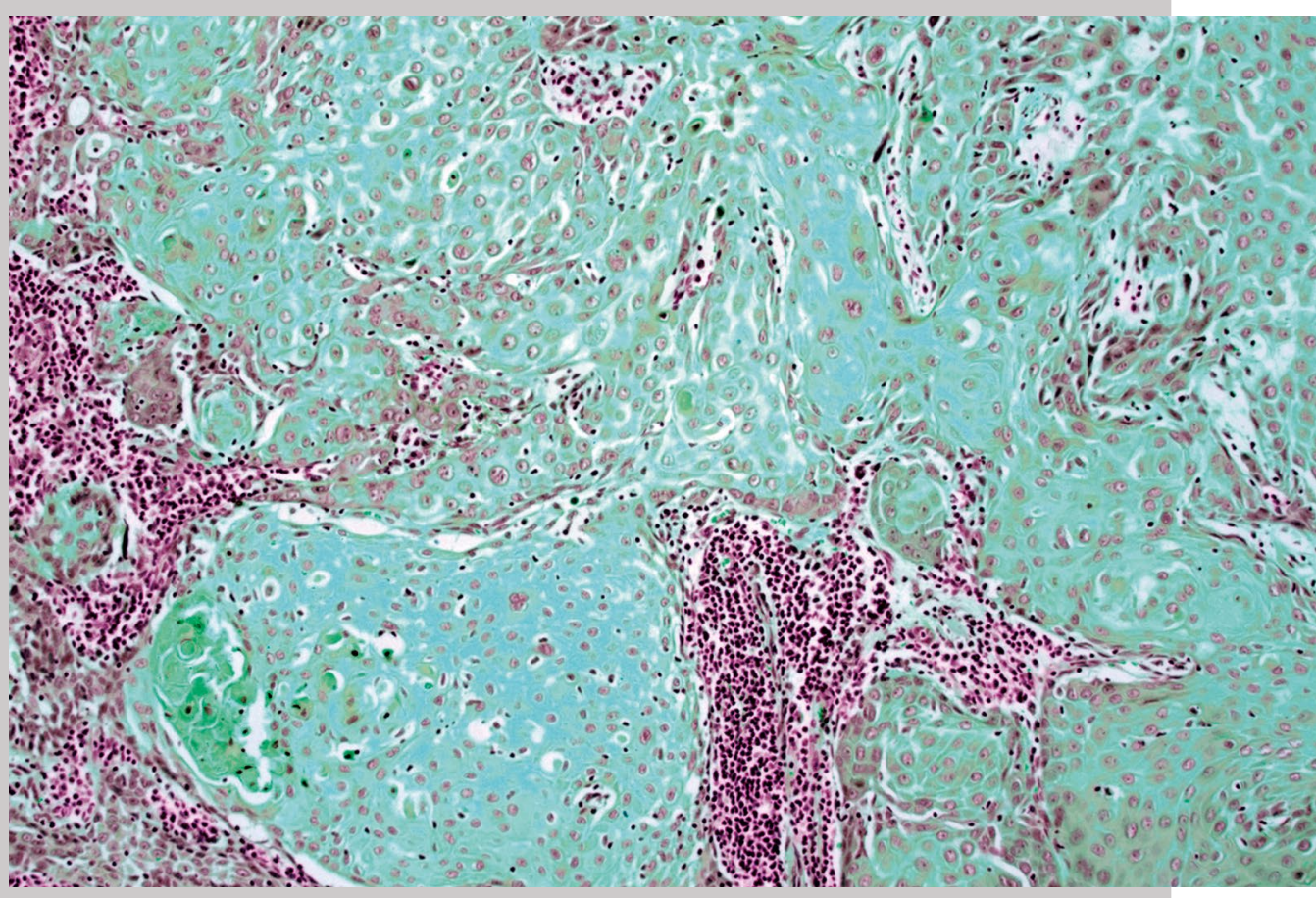

Dr Catherine Rutland, Clinical Director at Denplan, part of Simplyhealth said: 'We've worked together with the Oral Health Foundation for over 20 years on the Mouth Cancer Action Campaign, but we wanted to go one step further this year by spreading the mouth cancer awareness messages further and wider into the corridors of Westminster.

'Mouth cancer referrals will have been significantly reduced due to the COVID-19 pandemic restrictions last year and delays have been incurred by the dental backlog and access to NHS dentistry remaining difficult in certain areas. We urge the Government to consider these mouth cancer policy interventions. The longer the delay to implement these changes, the more lives could be lost to mouth cancer as possible cases go undetected. Top of the policy recommendation list is that we are calling on the Government to fund a public health awareness campaign on the signs and symptoms of mouth cancer.'

Recent research conducted by the Oral Health Foundation and Denplan shows that four-in-five UK adults have never been exposed to public health messaging around mouth cancer, leading to poor awareness of the early warning signs and risk factors.

Dr Rutland added: 'If people can easily recognise the risk factors and what to look out for in terms of changes in their mouth, health professionals will also be able to catch cases earlier. Late diagnosis of mouth cancer is becoming all too common and this will have a severe effect on a person's quality of life and their chances of survival.'

Commenting on the policy

recommendations proposed in the Charter, Dr Nigel Carter, Chief Executive of the Oral Health Foundation said: 'If these mouth cancer policy changes were put into action we could drive down case numbers and save the government a significant amount of money in oral cancer treatment costs. In England, the cost of head and neck cancer treatment was $£ 309$ m in 2010 11 and since then case numbers of mouth cancer have grown by around $67 \%$.

One of the key points in the mouth cancer charter is about the development of better technology to diagnose mouth cancers. During the pandemic, it has become more evident that innovation, data and technology are helping to make dentistry safer, faster and more accessible.

In addition to politicians and ministers, the Oral Health Foundation and Denplan are also asking dental professionals and other healthcare professionals to show their support and sign the Charter at www.dentalhealth.org/ mouth-cancer-action-charter. 